\title{
PEMBELAJARAN BAHASA INGGRIS MELALUI CONTENT-BASED INSTRUCTION
}

\author{
Suharso \\ Jurusan Pendidikan Bahasa Inggris \\ Fakultas Bahasa dan Seni, Universitas Negeri Yogyakarta
}

\begin{abstract}
Content-Based Instruction (CBI) is an approach to English language learning that combines subject matter contents with language skills. This approach can be employed to enable learners to master such contents and communicate them to other people. Like killing two birds with one stone, this approach equips learners with such contents and language skills simultaneously. There are two types of CBI, namely the content-driven program and the language-driven program. The former focuses on the contents of a particular subject matter as the basis of the learning activity organization, whereas the latter focuses on the language skills. One statement supporting this approach is that it enhances learners' motivation because the materials are authentic and contextual and learners need such materials in order to master subject matter contents.
\end{abstract}

Keywords: Content-Based Instruction, content-driven, language-driven

\section{A. PENDAHULUAN}

Di Indonesia sekarang ini banyak lembaga pendidikan, dari Taman Kanak-kanak (TK) sampai Perguruan Tinggi (PT), berlomba membuka kelas "internasional" dengan nama yang beragam. Pada tingkat TK sampai dengan Sekolah Menengah Atas (SMA) atau yang sederajat, ada yang menggunakan nama kelas imersi, kelas bilingual, dan Rintisan Sekolah Bertaraf Internasional (RSBI). Pada tingkat PT, ada yang menggunakan nama international class dan world class university. Terlepas dari nama yang digunakan, program tersebut bertujuan untuk meningkatkan mutu agar kelak lulusannya dapat bersaing di tingkat global atau internasional. Dari sisi hukum, program tersebut sah, karena dalam Undang-Undang Sistem Pendidikan Nasional No 20 Tahun 2003, Pasal 50, Ayat 3, disebutkan bahwa "Pemerintah dan/atau pemerintah daerah menyelenggarakan sekurang-kurangnya satu satuan pendidikan pada semua jenjang pendidikan untuk dikembangkan menjadi satuan pendidikan yang bertaraf internasional".

Salah satu ciri program tersebut adalah penggunaan bahasa Inggris sebagai bahasa pengantar untuk mata pelajaran atau mata kuliah tertentu. Khusus di Sekolah Menengah Pertama (SMP) dan SMA, mata pelajaran yang disampaikan dengan bahasa Inggris adalah mata pelajaran yang sering dilombakan dalam tingkat internasional melalui olimpiade. Mata pelajaran tersebut adalah Matematika dan Ilmu Pengetahuan Alam, yang meliputi Biologi, Fisika, dan Kimia (MIPA). Berdasarkan pengalaman, di dalam olimpiade penguasaan materi siswa Indonesia tidak kalah dengan siswa dari negara lain, tetapi menghadapi kendala untuk mengkomunikasikan gagasangagasannya. Oleh karena itu, pemerintah, melalui Departemen Pendidikan Nasional, memandang perlu program yang mempersiapkan siswa-siswa agar dapat bersaing di tingkat internasional. Program yang sudah direalisasikan adalah program RSBI, khususnya untuk SMP melalui Direktorat Pembinaan Sekolah Menengah Pertama (PSMP) dan SMA melalui Direktorat Pembinaan Sekolah Menengah Atas (PSMA).

Tanggapan masyarakat terhadap program RSBI beragam. Pihak yang setuju terhadap program tersebut menganggap bahwa 
untuk peningkatan mutu dan persaingan di tingkat internasional penggunaan bahasa Inggris sebagai bahasa pengantar dalam kegiatan belajar mengajar di sekolah-sekolah tidak dapat ditawar-tawar lagi. Perbaikan program dapat dilakukan secara bersamaan dengan pelaksanaannya. Pihak yang tidak setuju menganggap bahwa program tersebut suatu pemborosan, karena pemerintah harus mengeluarkan dana yang tidak sedikit dan tujuan program belum tentu dapat dicapai. Program tersebut dapat dilaksanakan hanya jika semua perangkat pendukungnya sudah siap.

Terlepas dari pandangan-pandangan tersebut, pelaksanaan program RSBI sudah berjalan. Dalam pelaksanaannya, memang ada beberapa kendala yang muncul. Kendala yang paling menonjol adalah penguasaan bahasa Inggris para guru MIPA yang secara umum masih belum memadai, dan penguasaan istilahistilah MIPA para guru bahasa Inggris yang rendah sehingga mereka tidak dapat membantu guru MIPA. Melalui Direktorat PSMP dan Direktorat PSMA, pelatihan untuk para guru, baik guru MIPA dan guru Bahasa Inggris, sudah sering dilaksanakan. Untuk guru MIPA, pelatihan ditekankan pada penguasaan bahasa Inggris sebagai bahasa pengantar dalam proses pembelajaran, dan untuk guru bahasa Inggris, pelatihan ditekankan pada penguasaan istilahistilah MIPA dalam bahasa Inggris. Melalui pelatihan seperti ini, guru MIPA dan guru bahasa Inggris diharapkan dapat bekerja sama dalam merancang kegiatan pembelajaran.

Artikel ini membahas pembelajaran bahasa Inggris melalui Content-Based Instruction (CBI) di SMP dan SMA. CBI dapat digunakan sebagai salah satu upaya untuk mengatasi kendala yang disebut di atas. Melalui CBI, siswa dapat meningkatkan kosakata yang digunakan dalam mata pelajaran tertentu, khususnya MIPA, dan mengkomunikasikannya sesuai dengan keperluan. Pembahasan dimulai dengan pengertian $\mathrm{CBI}$, diikuti dengan pembelajaran dengan $\mathrm{CBI}$, dan diakhiri dengan penutup.

\section{B. PENGERTIAN CONTENT-BASED INSTRUCTION}

Ada beberapa definisi CBI dengan penekanan yang berbeda dalam konteks pembelajaran bahasa. Brinton, Snow, \& Wessche (1989: 2) mendefinisikan CBI sebagai "the concurrent teaching of academic subject matter and second language skills" dan Richards \& Schmidt (2002: 115) mendefinisikannya sebagai "a programme in English as a second language in which the focus is on teaching students the skills they will need in regular classrooms, i.e. for learning in the content areas such as maths, geography, or biology". Kedua definisi ini mengemukakan CBI dalam konteks pembelajaran bahasa kedua.

Pengertian CBI yang lain dikemukakan oleh Crandall \& Tucker (1990: 187), yang mendefinisikannya sebagai "an approach to language instruction that integrates the presentation of topics or tasks from subject matter classes (e.g., math, social studies) within the context of teaching a second or foreign language" dan Wesche \& Skehan (2002: 220), yang mendefinisikannya sebagai "the integration of school or academic content with language teaching objectives". Kedua definisi ini menunjukkan bahwa CBI dapat diterapkan baik pada konteks pembelajaran bahasa kedua maupun pembelajaran bahasa asing.

Keempat definisi tersebut mewakili pengertian CBI secara umum, yaitu CBI sebagai pendekatan dalam pembelajaran bahasa Inggris yang menyatukan isi mata pelajaran dengan penggunaan bahasa agar para siswa kelak dapat mengkomunikasikan gagasan-gagasan yang relevan dengan mata pelajaran tertentu. Dengan demikian, pembelajaran bahasa Inggris dapat menggunakan, misalnya, bahan-bahan MIPA.

Nama CBI sering dikaitkan dengan nama-nama lain yang merujuk pada pengertian yang sama, yaitu Content and Language Integrated Learning (CLIL) dan English Across the Curriculum (EAC). Nama-nama tersebut tidak dapat dilepaskan dengan English for Specific Purposes (ESP), yang sering 
dikontraskan dengan English for General Purposes (EGP). Menurut Johnson \& Johnson (1999: 105) ESP pada awalnya memiliki dua cabang, yaitu English for Academic Purposes (EAP) dan English for Occupational Purposes (EOP). Namun dalam perkembangan selanjutnya, nama-nama lain juga muncul, seperti English for Science and Technology (EST) dan English for Educational Purposes (EEP). CBI adalah salah satu nama yang muncul dalam perkembangan ESP.

Salah satu manfaat dari CBI adalah bahwa penggunaan materi dari mata pelajaran tertentu sebagai bahan pembelajaran bahasa dapat memaksimalkan pajanan siswa pada bahasa yang dipelajarinya. Pajanan ini bersifat kontekstual karena sesuai dengan kebutuhan siswa. Pembelajaran melalui CBI yang berhasil dapat menjadikan siswa menguasai baik bahasa maupun isi mata pelajaran melalui proses timbal balik.

Dalam konteks pembelajaran bahasa Inggris sebagai bahasa asing, melalui CBI siswa perlu terlibat dalam beragam kegiatan agar dapat menguasai bahasa sasaran dan isi mata pelajaran. Nunan (2004: 132) menyebutkan beberapa manfaat dari CBI. Manfaat-manfaat tersebut antara lain "an organic, analytical approach to language development" dan "a framework within which learners can have sustained engagement on both content mastery and second language acquisition". Meskipun Nunan menyebutkan manfaat tersebut dalam konteks bahasa kedua, manfaat dalam konteks bahasa asing tidak jauh berbeda. Selanjutnya, Nunan (2004: 132), dengan mengutip Brinton (2003), menyebutkan lima prinsip dalam CBI:

1. Kegiatan pembelajaran didasarkan pada isi, bukan pada aspek kebahasaan.

2. Keterampilan hendaknya terintegrasi.

3. Siswa hendaknya secara aktif terlibat dalam semua tahap proses pembelajaran.

4. Isi hendaknya dipilih berdasarkan relevansinya dengan kebutuhan siswa yang sejalan dengan tujuan akademik.

5. Bahan-bahan dan tugas-tugas hendaknya otentik.

Dengan demikian, melalui CBI siswa mempelajari bahasa Inggris melalui topik-topik dalam mata pelajaran Matematika, Biologi, Fisika, dan Kimia, dan sekaligus mempelajari mata pelajaran tersebut dengan bahasa pengantar bahasa Inggris. Dengan cara ini siswa dapat diharapkan mengkomunikasikan baik secara lisan maupun tertulis gagasangagasan yang relevan dengan mata pelajaran tersebut, karena pembelajaran bahasa Inggris menggunakan bahan darinya.

Penerapan CBI dalam praktik dapat ditempuh dengan berbagai cara. Crandall dkk. (1987) mengemukakan dua model pembelajaran bahasa Inggris melalui CBI. Model yang pertama adalah content-driven (berdasarkan isi) dan yang kedua adalah language-driven (berdasarkan bahasa). Ciriciri dari kedua model tersebut disajikan dalam Tabel 1. 
Tabel 1. Ciri-ciri CBI Berdasarkan Isi dan CBI BerdasarkanBahasa

\begin{tabular}{|c|c|}
\hline Berdasarkan Isi & Berdasarkan Bahasa \\
\hline Isi diajarkan dengan Bahasa Inggris. & $\begin{array}{c}\text { Isi digunakan untuk mempelajari } \\
\text { Bahasa Inggris. }\end{array}$ \\
\hline Pembelajaran isi menjadi prioritas. & Pembelajaran bahasa menjadi prioritas. \\
\hline Pembelajaran bahasa bersifat sekunder. & Pembelajaran isi bersifat sekunder. \\
\hline $\begin{array}{l}\text { Tujuan pembelajaran isi ditentukan oleh } \\
\text { kompetensi dalam mata pelajaran. }\end{array}$ & $\begin{array}{c}\text { Tujuan pembelajaran bahasa ditentukan oleh } \\
\text { kompetensi dalam kebahasaan. }\end{array}$ \\
\hline $\begin{array}{l}\text { Guru perlu memilih tujuan pembelajaran } \\
\text { bahasa. }\end{array}$ & $\begin{array}{l}\text { Guru perlu memilih isi yang akan } \\
\text { diintegrasikan. }\end{array}$ \\
\hline $\begin{array}{l}\text { Evaluasi siswa didasarkan pada } \\
\text { penguasaan isi. }\end{array}$ & $\begin{array}{l}\text { Evaluasi siswa didasarkan pada kemahiran/ } \\
\text { keterampilan berbahasa. }\end{array}$ \\
\hline
\end{tabular}

Pembagian di atas tidak bersifat pilah. Artinya guru dapat secara luwes menerapkan CBI sesuai dengan keadaan siswanya; apakah dia cenderung menerapkan CBI yang berdasarkan isi atau yang berdasarkan bahasa. Dalam CBI yang berdasarkan isi, pembelajaran siswa terhadap isi mata pelajaran lebih penting daripada pembelajaran bahasa. Penguasaan isi mata pelajaran menjadi tujuan utama pembelajaran. Dalam CBI yang berdasarkan bahasa, isi mata pelajaran digunakan sebagai sarana untuk memperkaya tujuan pembelajaran bahasa. Pembelajaran isi mata pelajaran tidak menjadi tujuan utama.

Kedua model yang diuraikan di atas mirip dengan bentuk CBI yang dikemukakan oleh Wesche \& Skehan (2002), yaitu bentuk lemah (weak form) dan bentuk kuat (strong form). Bentuk lemah adalah CBI yang bertujuan mengembangkan kemahiran komunikatif siswa melalui silabus kebahasaan yang disusun berdasarkan isi mata pelajaran tertentu. Silabus disusun berdasarkan keterampilan berbahasa dan diorganisasikan dengan mengacu pada teks-teks yang relevan dengan mata pelajaran, yang berfungsi sebagai program pendukung penguasaan keterampilan berbahasa.
Bentuk kuat adalah CBI yang menekankan pada isi mata pelajaran. Tujuan utama dari bentuk ini adalah penguasaan mata pelajaran. Silabus disusun berdasarkan tema mata pelajaran dan diorganisasikan berdasarkan urutan topik mata pelajaran, dan berfungsi sebagai program pendukung penguasaan mata pelajaran. Penguasaan keterampilan berbahasa bersifat sekunder.

Di antara kedua bentuk di atas, ada bentuk gabungan yang dapat dilaksanakan dengan memperhatikan kondisi siswa. Wesche \& Skehan (2002) menyatakan bahwa dalam pelaksanaannya CBI dapat menggunakan dua bahasa atau lebih (two or more instructional languages). Bahasa pengantar dalam CBI tidak hanya bahasa Inggris. Dengan demikian, pada konteks Indonesia, misalnya, penggunaan bahasa pengantar dapat berupa campuran antara bahasa Indonesia dan bahasa Inggris. Apapun bentuknya, keberhasilan CBI dalam menjadikan siswa menguasai isi dan bahasa akan bergantung pada apakah kegiatan belajar mengajar yang menggunakan CBI secara sistematik mempertimbangkan kemampuan siswa. Artinya, CBI hanyalah sebagai salah satu pendekatan, yang keberhasilannya bergantung pada banyak faktor. 


\section{PEM B E LA JARA N BAHASA INGGRIS MELALUI CBI}

Di bagian yang terdahulu telah disebutkan bahwa CBI dapat digunakan dalam konteks pembelajaran bahasa Inggris sebagai bahasa kedua atau sebagai bahasa asing. Dalam konteks bahasa kedua, di luar kelas bahasa Inggris siswa memiliki pajanan yang cukup karena bahasa Inggris digunakan sebagai alat komunikasi utama. Dalam konteks bahasa asing, di luar kelas bahasa Inggris siswa tidak memiliki pajanan yang cukup karena bahasa Inggris tidak digunakan sebagai alat komunikasi utama. Di sekolah-sekolah di Indonesia, bahasa Inggris pada umumnya diajarkan sebagai bahasa asing. Oleh karena itu, guru yang akan menggunakan pendekatan CBI perlu mempertimbangkan sejumlah faktor penting.

Salah satu faktor tersebut adalah organisasi kegiatan belajar mengajar. Pada tahap awal kegiatan pembelajaran, guru perlu secara eksplisit mengajarkan kosakata yang akan digunakan dalam kegiatan pembelajaran inti. Guru dapat menyediakan glossary (daftar kata yang digunakan dalam topik yang dipelajari). Pembekalan kosakata ini penting agar siswa terbantu dalam memahami isi dan kemudian mengkomunikasikannya. Bernier (Lingley, 2006) menyatakan bahwa untuk keperluan tersebut guru hendaknya membantu siswa dengan konteks bahasa pertama dan perlu menyesuaikan teknik atau metode mengajarnya agar siswa dapat memahami isi yang menjadi sasarannya. Misalnya, di dalam teks Matematika ada frasa 'least common multiple', di Biologi ada kata 'taproot', di Fisika ada 'states of matter' dan di Kimia ada 'chemical compound'. Guru perlu menjelaskan kepada siswa bahwa frasa-frasa tersebut dalam bahasa Indonesia 'kelipatan persekutuan terkecil', 'akar tunggang', 'wujud benda', dan 'senyawa kimia'. Konsep-konsep tersebut sudah dikenal siswa dalam mata pelajaran tersebut.

Pada kegiatan pembelajaran inti, guru perlu memberi contoh yang berupa model teks baik lisan maupun tulis sesuai dengan keterampilan yang akan dilatihkan. Seperti yang disebutkan oleh Nunan (2004), pembelajaran bahasa Inggris yang menggunakan pendekatan CBI sebaiknya mengintegrasikan sejumlah keterampilan. Jika alokasi waktu memungkinkan, dalam satu pertemuan keempat keterampilan berbahasa, yaitu menyimak, berbicara, membaca, dan menulis, dapat digabungkan sekaligus. Jika integrasi keempat keterampilan tidak mungkin dilakukan dalam satu pertemuan, integrasi setidak-tidaknya dua keterampilan dapat dilakukan. Pada kegiatan pembelajaran inti, keterampilan berbahasa dilatihkan berdasarkan isi teks yang relevan dengan mata pelajaran. Siswa dilatih mengeksplorasi isi teks melalui kegiatan menyimak, berbicara, membaca, dan menulis, sesuai dengan keterampilan berbahasa yang ditekankan.

Pada kegiatan penutup, siswa diarahkan untuk membuat kesimpulan mengenai apa yang telah mereka pelajari dan merefleksikan apa-apa yang mudah dan sulit dalam kegiatan pembelajaran. Kegiatan ini dapat dilakukan baik secara lisan maupun tertulis. Dengan cara ini, siswa dapat mengungkapkan gagasan, yang berarti dapat berkomunikasi baik secara lisan maupun tertulis.

\section{CONTOH PENERAPAN CBI}

Berikut ini contoh sederhana kegiatan belajar mengajar bahasa Inggris yang menggunakan pendekatan CBI di tingkat SMP. Bahan pembelajaran diambil dari Biologi dengan topik Plants. Keterampilan berbahasa yang dilatihkan adalah menyimak, berbicara, membaca, dan menulis. Kompetensi dasar yang akan dicapai adalah merespon dan mengungkap makna dalam bentuk teks description .

\section{Kegiatan Pembelajaran Awal}

Guru menuliskan di papan tulis leaves, flower, plant, dirt, soil, pot, roots, stem, above, below, under, in, atau kata-kata lain yang sesuai. Guru membawa tanaman ke dalam kelas atau menyuruh siswa melakukannya. Guru meminta siswa untuk mengamati tanaman tersebut dan 
mendiskusikannya, dengan menggunakan language expression (ungkapan), seperti "Look at this pretty plant. It's in a pot. See its green leaves. Here's a flower. It's on the stem." Ungkapan yang lain dapat digunakan sejauh ungkapan tersebut sesuai konteks. Kata-kata yang ditulis di papan tulis dijelaskan kepada siswa bahwa kata-kata tersebut akan digunakan pada kegiatan berikutnya. Guru meminta siswa untuk memperhatikan ejaan dan ucapan katakata tersebut.

\section{Kegiatan Pembelajaran Inti}

Untuk melatih keterampilan menyimak, guru dapat menyuruh siswa untuk melakukan sesuatu dengan Total Physical Response (melakukan perintah), misalnya "Point to the leaves". Untuk melatih keterampilan berbicara, guru dapat menyuruh siswa menggambar tanaman yang lengkap (daun, bunga, cabang, dan akar) di papan tulis, dan meminta siswa menyebutkan nama-nama bagian tanaman tersebut dalam bahasa Inggris. Guru dapat menanyakan kepada siswa tentang tanaman tersebut dengan pertanyaan seperti "What color are the leaves/the stem?", "How does the leaf/stem feel?", "Is it smooth/rough?", "What's above/below the dirt?", atau pertanyaan lain yang relevan. Dengan menjawab pertanyaan-pertanyaan tersebut, siswa berlatih keterampilan berbicara. Untuk melatih keterampilan membaca, guru dapat memberikan kepada siswa teks tulis tentang tanaman dari buku teks Biologi, koran atau majalah dan meminta siswa mendiskusikannya. Untuk melatih keterampilan menulis, guru dapat meminta siswa mendeskripsikan secara tertulis gambar-gambar di papan tulis yang digunakan juga untuk melatih keterampilan berbicara. Ini semua dapat dilakukan jika alokasi waktu memungkinkan. Jika waktu terbatas, kegiatan inti dapat dilakukan dengan mengintegrasikan setidak-tidaknya dua keterampilan.

\section{Kegiatan Penutup}

Bersama-sama guru, siswa menyimpulkan dan merefleksikan butir-butir yang telah mereka pelajari. Guru dapat mengulangi penjelasan terhadap butir-butir penting yang telah dipelajari jika hasil refleksi menunjukkan bahwa siswa masih menjumpai kesulitan.

\section{E. PENUTUP}

CBI adalah pendekatan pembelajaran yang mengintegrasikan isi mata pelajaran dengan bahasa. Alasan yang menjadi dasar CBI adalah bahwa 'a second language is learned most effectively when used as the medium to convey informational content of interest and relevance to the learner' (Brinton, Snow \& Wesche, 1989: vii). Tidak seperti pendekatan pembelajaran bahasa pada umumnya, yang biasanya didasarkan pada penyajian dan latihan tata bahasa dan kosakata yang tidak selalu kontekstual, CBI memberikan kepada siswa keterampilan berbahasa yang bermakna dan kontekstual melalui bahan-bahan yang otentik berdasarkan tema-tema dalam mata pelajaran tertentu.

Karena CBI berkaitan dengan isi mata pelajaran (Carson, Taylor \& Fredella, 1997), tidak mudah bagi guru untuk menyadari sepenuhnya bahwa ia sedang mengajarkan bahasa. Guru yang mengajar bahasa Inggris dengan pendekatan CBI dapat lupa akan tugas pokoknya, yaitu mengajarkan bahasa Inggris, karena lebih mementingkan mengajarkan isi mata pelajaran tertentu. CBI adalah pendekatan pengajaran bahasa, sehingga guru tetap harus menitikberatkan pada pembelajaran bahasa dan siswanya adalah siswa yang sedang belajar berbahasa dengan segala permasalahan kebahasaan yang harus mereka hadapi. Misalnya, mereka harus tetap belajar berkomunikasi secara perpasangan dan dalam kelompok kecil. Mereka harus tetap dapat menerapkan strategi menyimak, berbicara, membaca, dan menulis.

Dalam konteks pembelajaran bahasa Inggris di Indonesia, sampai pada tahap tertentu, guru-guru bahasa Inggris di SMP dan SMA sudah melaksanakan pembelajaran melalui CBI. Berdasarkan Standar Isi Mata Pelajaran Bahasa Inggris untuk RSBI, Standar 
Isi pada Standar Nasional diberi tambahan yang berupa muatan "keilmuan", yaitu yang berkaitan bidang MIPA. Dalam pembelajaran bahasa Inggris, guru dituntut memilih bahanbahan ajar yang berkaitan dengan MIPA. Banyak buku teks bahasa Inggris yang telah memasukkan topik tentang ilmu pengetahuan. Jika guru-guru menggunakan buku semacam itu sebagai sumber bahan, mereka berarti sudah menggunakan CBI dalam proses pembelajaran bahasa Inggris. Tugas-tugas di luar kelas yang harus dikerjakan oleh siswa seperti mencari artikel tentang Global Warming untuk kemudian didiskusikan di dalam kelas sampai pada tingkat tertentu juga berkaitan dengan prinsip-prinsip dalam CBI. Praktik-praktik yang demikian dapat dikembangkan secara sadar dengan menggunakan prinsip-prinsip CBI secara lebih terstruktur dan sistematik agar tujuan membekali siswa dengan penguasaan bahasa Inggris untuk kepentingan komunikasi ilmiah dapat dicapai. Hal yang perlu selalu diingat adalah mereka guru bahasa Inggris yang melatih keterampilan berbahasa Inggris siswa, bukan guru MIPA yang membekali siswa dengan isi mata pelajaran tersebut.

\section{DAFTAR PUSTAKA}

Brinton, D.M., Snow, M.A., \& Wesche, M.B. 1989. Content-based Second Language Instruction. Boston: Heinle $\&$ Heinle.

Carson, J.G., Taylor, J.A. \& Fredella, L. 1997. The role of content in task-based EAP instruction. In M. A. Snow \& D. M. Brinton (Eds.). The Content-based classroom. (pp. 367-370) White Plains, NY: Longman.

Crandall, J. dkk. 1987. Integrating language and content instruction for language minority students. Teacher Resource Guide Series, Number 4 $\mathrm{S}$ e p t e m b e r 1987. http://www.ncela.gwu.edu/pubs/classi $\mathrm{cs} / \operatorname{trg} / 04$ integrating.htm.

Crandall, J. and Tucker, G. R. 1990. Contentbased instruction in second and foreign languages. In A. Padilla, H. H. Fairchild and C. Valadez (eds.) Foreign Language Education: Issues and Strategies. Newbury Park, CA: Sage.

Johnson, K. \& Johnson, H. 1999. Encyclopedic Dictionary of Applied Linguistics. Oxford: Blackwell Publishers.

Lingley, D. 2006. A Task-based approach to teaching: a content-based Canadian studies course in an EFL context. Asian EFL Journal. Vol. 8, Issue 3. September 2006. http://www.asian-efljournal.com/Sept 06 dl.php

Nunan, D. 2004. Task-based Language Teaching. Cambridge: Cambridge University Press.

Richards, J.C. \& Schmidt, R. 2002. Longman Dictionary of Language Teaching and Applied Linguistics. Harlow: Pearson Education Limited.

Undang-undang Republik Indonesia Nomor 20 Tahun 2003 tentang Sistem Pendidikan Nasional.

Wesche, M. B. \& Skehan, P. 2002. Communicative, task-based, and content-based language instruction. In R. B. Kaplan (Ed.) The Oxford Handbook of Applied Linguistics. Oxford: Oxford University Press. 